\title{
The expression of membranous complement inhibitors CD46, CD55 and CD59 in the primary and metastatic colon cancer cell lines derived from the same patient
}

\author{
EWA WILCZEK ${ }^{1}$, ALEKSANDER WASIUTYNSKI ${ }^{1}$, DARIUSZ SLADOWSKI \\ GRZEGORZ M. WILCZYNSKI ${ }^{3}$, BARBARA GORNICKA ${ }^{l}$ \\ ${ }^{1}$ Department of Pathology, Medical University of Warsaw, Poland \\ ${ }^{2}$ Department of Transplantology and Central Tissue Bank, Centre for Biostructure, Medical University of Warsaw, Poland \\ ${ }^{3}$ Laboratory of Molecular and Systemic Neuromorphology, Nencki Institute of Experimental Biology, Polish Academy of Sciences, Warsaw, \\ Poland
}

\begin{abstract}
Membrane-bound complement regulatory proteins protect cells from the complement-based destruction and affects many vital immunological functions. As was shown by many studies, overexpression of these proteins on cancer cells may have a negative influence on the therapeutic effect of monoclonal antibodies and immunotherapy. The most commonly observed complement inhibitors on cancer cells are CD46, CD55 and CD59. In the presented work we evaluated the expression and immunoreactivity pattern of these three regulators in two colon cancer cell lines, one derived from the primary tumor (SW480), and the other from the lymph node metastasis (SW620). Both cell lines were derived from the same patient. We found that in the SW480 cells the expression of all inhibitors was heterogeneous, within this cell line many subpopulations of cells existed, which displayed different levels of complement inhibitors. On the contrary, on SW620 cells the immunoreactivity of examined inhibitors was more homogeneous, virtually all examined cells displayed complement inhibitors immunoreactivity on the same level. The most prominent in both cell lines was the CD46 expression on the cell surface. Our results indicate that during carcinogenesis progression only these cancer cells may spread, migrate and form metastatic foci, which possess more complement inhibitors on their cell surface. Modulation of the function of membrane-bound complement inhibitors may have beneficial influence on such strategies as immunotherapy with monoclonal antibodies.
\end{abstract}

Key words: complement inhibitors, colon cancer, metastasis.

(Centr Eur J Immunol 2013; 38 (4): 549-555)

\section{Introduction}

Colon cancer is one of the most common causes of cancer-related deaths worldwide. Treatment of patients with an advanced stage of colon cancer is often unsuccessful, thus new possible treatment options are searched for. One of the treatment methods is the use of monoclonal antibodies directed against cancer cells. This kind of treatment was found to be successful in the case of rituximab in B-cell non-Hodgkin's lymphoma and trastuzumab in breast cancer. So far for colorectal cancer treatment such antibodies as cetuximab, bevacizumab and panitumumab has been applied [1]. However, one of the main factors, which limit the efficacy of immunotherapy is the presence of complement inhibitors on cancer cells. This kind of regulation inhibits one of the mechanisms targeted by the immunotherapy, i.e. complement-dependent cytotoxicity on cancer cells, thus influencing the overall response to therapy. These inhibitors are able to inactivate complement cascade, at different steps and facilitate evading complement-mediated immune response.

The complement system consists of about 30 proteins which upon activation acts in a cascade manner. The initial steps start at the cell membrane, where upon antibody connection and activation lead to the formation of enzymatic complexes, called C3 and C5 convertases, what ultimately leads to the formation of the membrane attacks complex (MAC). This structure forms many pores on the cell surface what ends with the cell destruction [2]. 
The most important membrane-bound complement regulators are CD46, CD55 and CD59. The first two regulators act during initial steps of complement activation, whereas the latter one acts on the last step and blocks the MAC formation. CD46 possesses cofactor activity for serum factor I and inactivation of complement components $\mathrm{C} 3 \mathrm{~b}$ and $\mathrm{C} 4 \mathrm{~b}$. It was initially identified as a protein binding $\mathrm{C} 3 \mathrm{~b}$ and $\mathrm{C} 4 \mathrm{~b}$ on the surface of peripheral blood cells $[3$, 4]. CD55 is a glycoprotein associated with the cell surface via glycophosphatidylinositol (GPI). CD55 can be found on virtually all cells which come into contact with components of the complement system, including peripheral blood cells, epithelial and endothelial cells [5-9]. This inhibitor accelerates the degradation of C 3 and C5 convertases, both in the classical and alternative complement activation pathways. CD59, like CD55, is a protein attached to the cell membrane via GPI. This protein is widely distributed on the surface of cell membranes [10]. By binding the CD59 molecule to the C5b-8, the C9 subunit cannot be properly folded $[11,12]$. This prevents the exposure of the $\mathrm{C} 9$ fragment responsible for attachment of additional components $\mathrm{C}$, what prevents the creation of a complete membrane attack complex and pore formation.

The complement inhibitors, as was reported in literature data, are usually overexpressed on cancer cells. In current work we show the presence of three main complement inhibitors CD46, CD55 and CD59 in the primary and metastatic cancer cell lines derived from the same patient. In our study we attempted to determine whether the expression pattern of complement inhibitors changes as cancer progression follows and metastasis occurs.

\section{Cell lines and cell culture}

Colon carcinoma cell line SW480 was obtained from the American Type Culture Collection, and SW620 was from the Hirszfeld Institute, Polish Academy of Sciences. Both cell lines were previously classified on the morphological and cytogenetic level [13]. Cells were grown in RPMI 1640 medium (GIBCO, USA) supplemented with $10 \%$ fetal bovine serum (Invitrogen, USA) and $1 \%$ antibiotic-antimycotic (GIBCO), and maintained in a humidified atmosphere with $5 \% \mathrm{CO}_{2}$ at $37^{\circ} \mathrm{C}$. For fluorescence analyses, cells were grown in cell culture 'Chamberslides' (Nunc, Germany).

\section{Immunofluorescence studies}

For CD55, CD46 and CD59 detection, MCA1614, MCA2113 and MCA1024 mouse monoclonal antibodies (Serotec, United Kingdom) were used. For indirect immunofluorescence analyses, donkey anti-mouse Alexa488 and, donkey anti-mouse Alexa555 secondary antibodies as well as Streptavidin-Alexa488 (all from Molecular Probes, USA) were employed. In some experiments cancer cells were marked with phalloidin-TRITC (Sigma-Al- drich, USA) as a counterstain. Lastly, the specimens were mounted with Vectashield with DAPI (Vector Laboratories, USA) and analyzed under the Leica DMI6000 Fluorescence Microscope. For confocal imaging, Leica TC SP2 Confocal Microscope (Leica Microsystems, Germany), with $\mathrm{Ar}(488 \mathrm{~nm}), \mathrm{GeNe}(543 \mathrm{~nm})$ laser lines for the excitation of Alexa 488 and Alexa 555, respectively, was used. To avoid cross-talk between the fluorophores, we carefully adjusted the spectral ranges of detectors and scanned images sequentially.

\section{Results}

CD46 immunofluorescence analysis showed that this molecule has mainly a membranous localization of high intensity. Additionally, there was also homogeneous cytoplasmic staining seen, but to a much lesser degree. This type of labeling was present in both SW480 and SW620 cell populations. However, in SW480 cells quite a large variation in the intensity of CD46 immunoreactivity was observed, most of the cell population showed a moderate reaction, a smaller percentage of cells displayed strong CD46 immunoreactivity. In the SW620 cell line, the level of intensity of the reaction was rather uniform, in most cells CD46 immunoreactivity showed strong labeling (Fig. 1).

CD55 immunoreactivity was located mainly in the cytoplasm in the form of granules, sometimes more concentrated at the cell membrane. Most of cells, both SW480 and SW620 had CD55 expression, but the reaction showed a very weak intensity (Fig. 2). No differences were noted in the type and distribution of reactions within cells of both cell lines.

The anti-CD59 antibody in both cell lines showed a similar pattern of reaction (Fig. 3). Common was immunoreactivity in a form of large granules seen both in the cytoplasm and cell membrane. The immunofluorescence intensity in primary colon cancer cells was comparable to the intensity in cells derived from metastasis. Additionally, in the SW480 cell line, immunoreactivity was observed in the cell protrusions. In the metastatic cell line often membranous pattern of reaction dominated. In the SW480 cell line, however, both the membranous and cytoplasmic reaction were expressed equally. The control immunoreaction, where antibodies were replaced with the equivalent amount of immunoglobulins showed no immunoreactivity (Fig. 4).

To summarize, the immunofluorescence studies of three regulators examined, the immunoreactivity level of these proteins was in general similar in both cancer cell lines. However the diverse, heterogeneous staining among the SW480 primary cell line, was rarely detected in the metastatic SW620 cell line, where uniform staining of cancer cells was more common. 


\section{SW620}
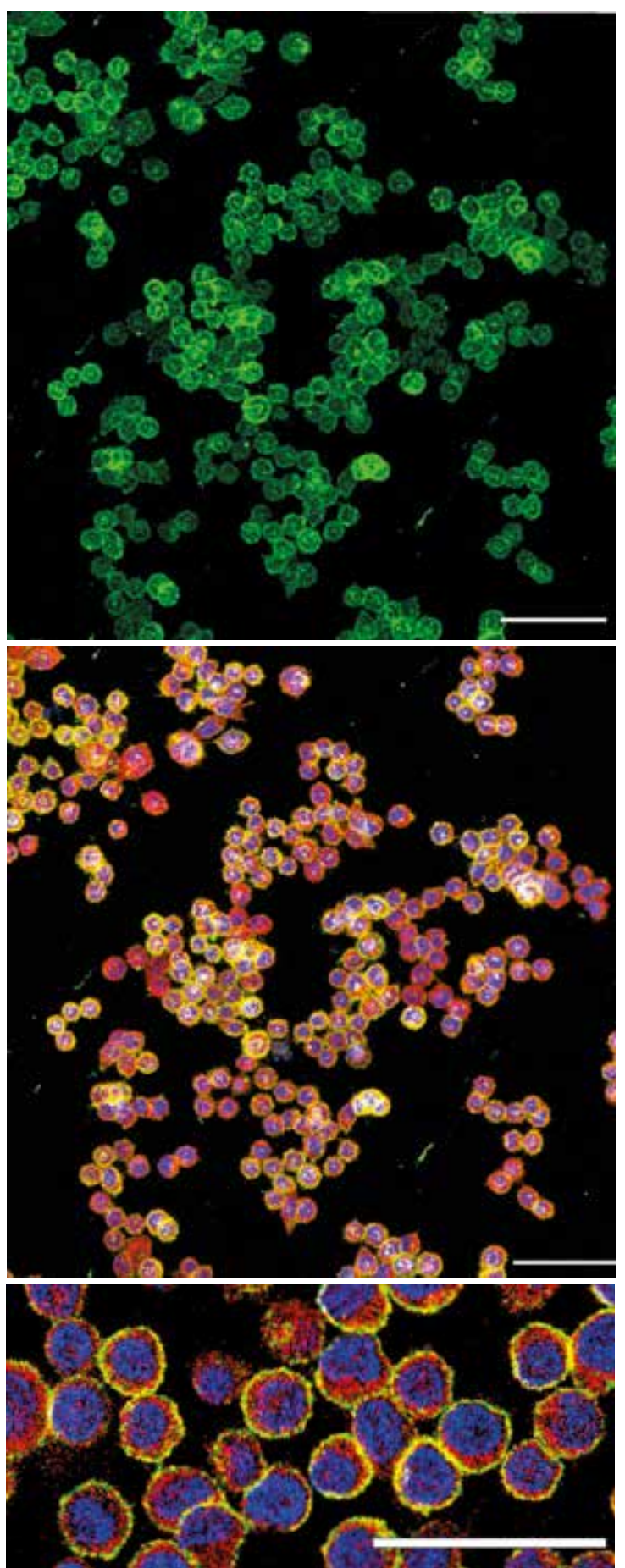

\section{SW480}

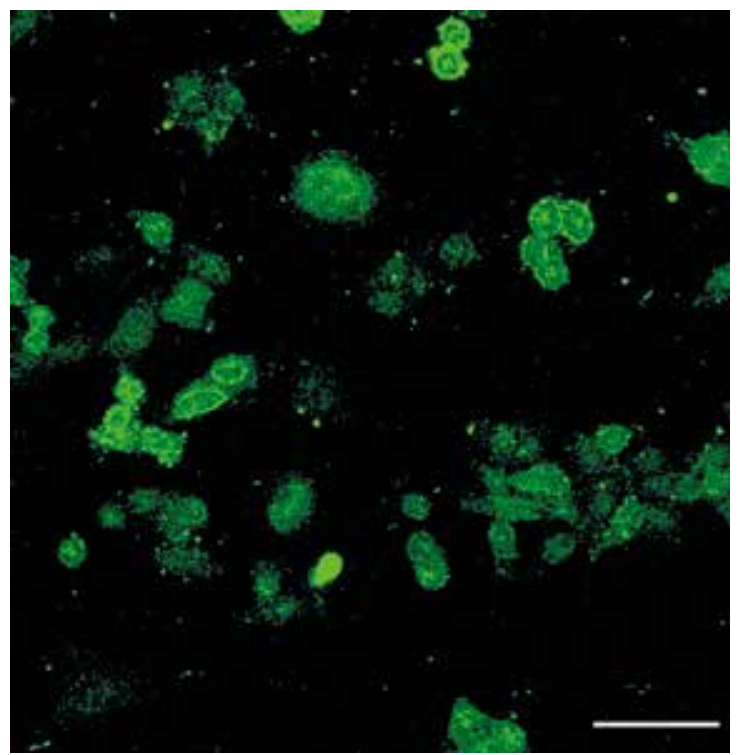

CD46

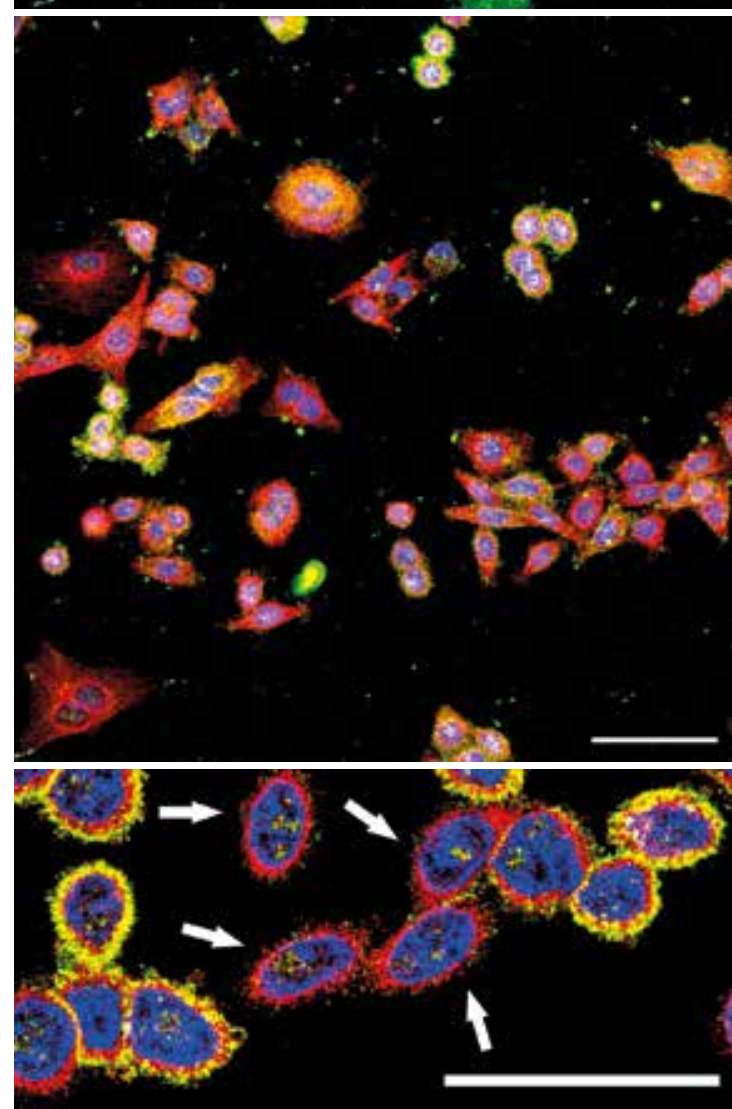

CD46 $\alpha$-tubulin

DAPI

Fig. 1. CD46 immunoreactivity (green) in SW480 and SW620 cell lines. To visualize cell morphology $\alpha$-tubulin staining was applied (red), cell nuclei were stained with DAPI (blue); note the lack of the CD46 staining within a subpopulation of SW480 cancer cells (arrows) and uniform staining of SW620 cells; scale bar $50 \mu \mathrm{m}$ 
SW620
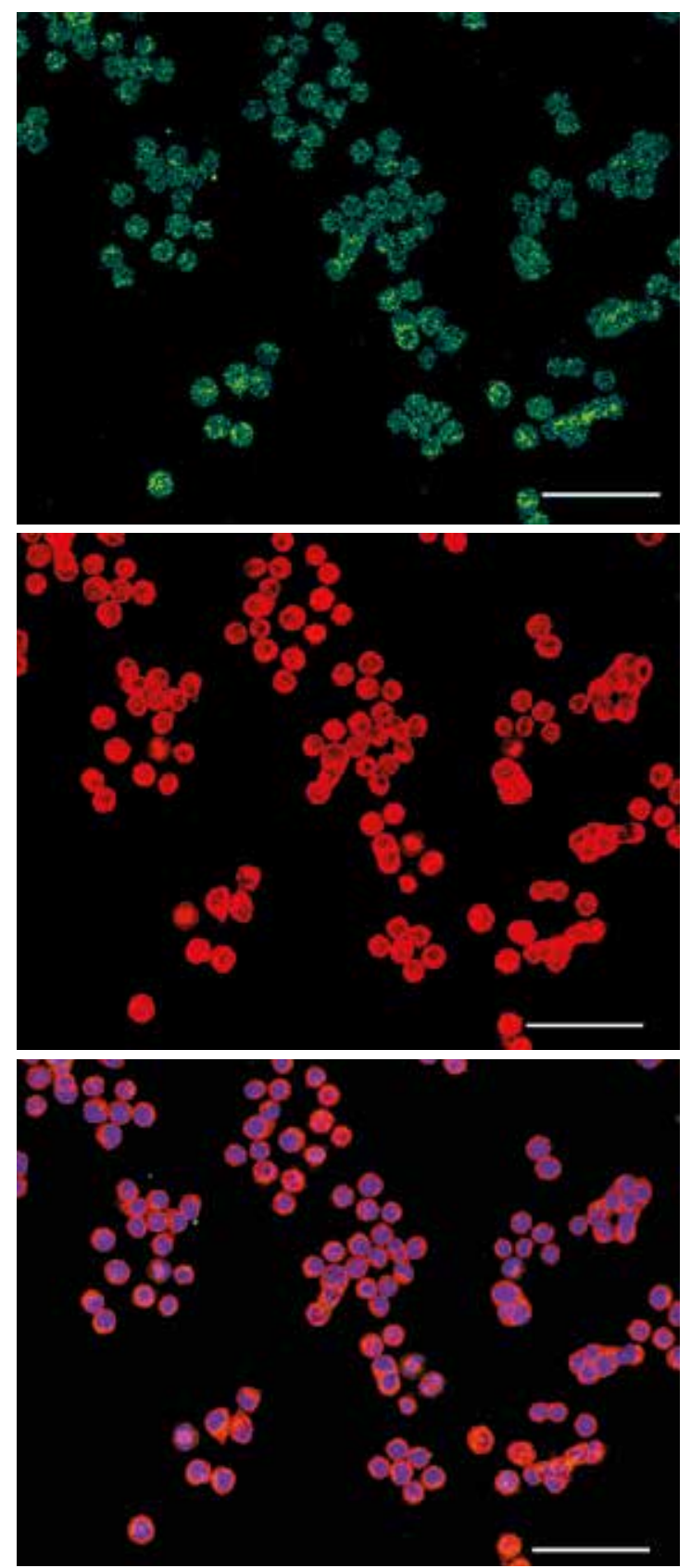

SW480
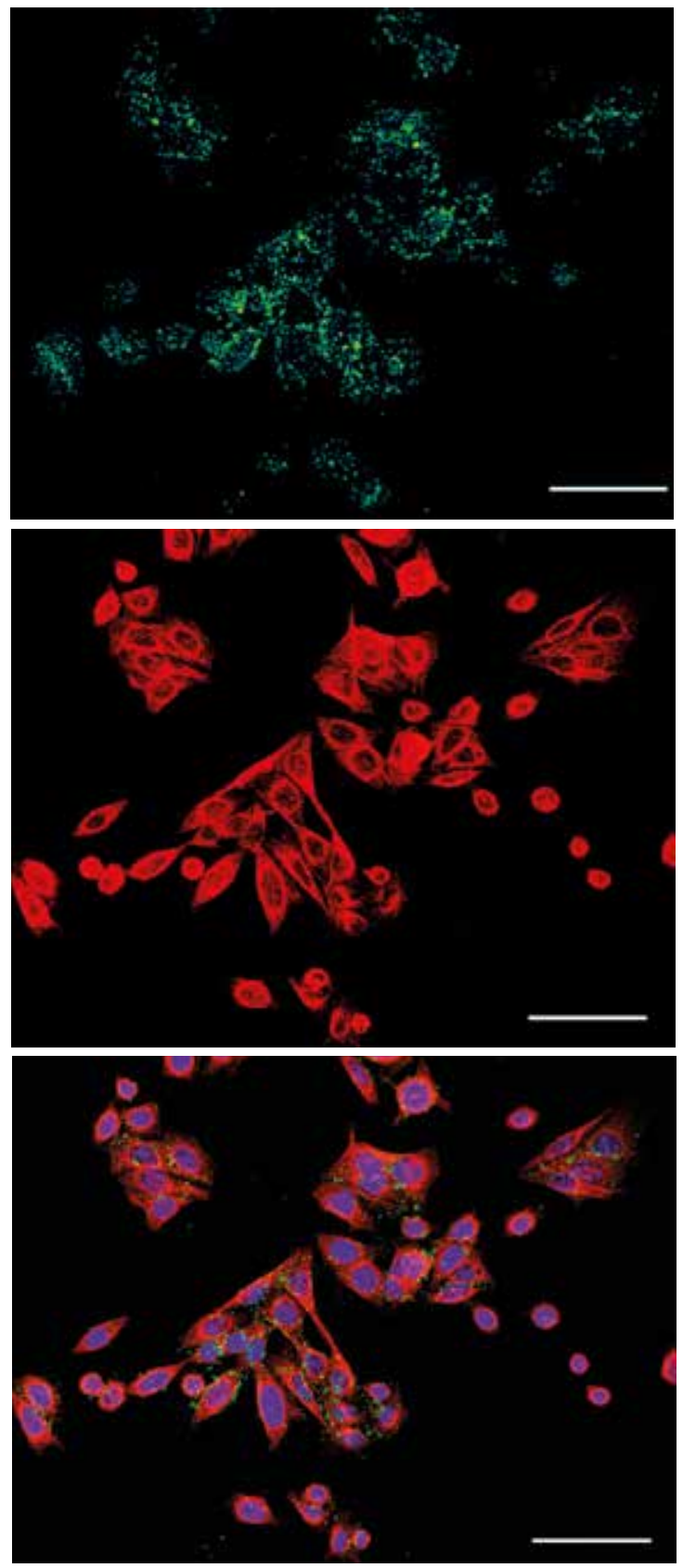

CD55

$\alpha$-tubulin

CD55 $\alpha$-tubulin DAPI

Fig. 2. CD55 immunoreactivity (green) in SW480 and SW620 cell lines. To visualize cell morphology $\alpha$-tubulin staining was applied (red), cell nuclei were stained with DAPI (blue); scale $50 \mu \mathrm{m}$

\section{Discussion}

Studies on cell lines derived from the primary and metastatic foci of colon cancer revealed that the most profoundly expressed among membrane-bound complement inhibitors is CD46 molecule. CD55 and CD59 are expressed less abundantly. The more homogenous staining of inhibitors in the metastatic SW620 cell line suggests the expansion of these cancer cells from the primary foci which possess these regulators on its surface.
Membrane-bound regulators in various cancer types have been extensively described in the literature. Although there is no definite opinion regarding the level of expression of these proteins, the majority of studies have shown that many tumors expresses at least two out of three main membranous inhibitors: CD46, CD55 and CD59. The expression level of these proteins varies depending on the type of tumor, the degree of differentiation, and, in part, on the clinical stage. In some studies, the lack of CD55 

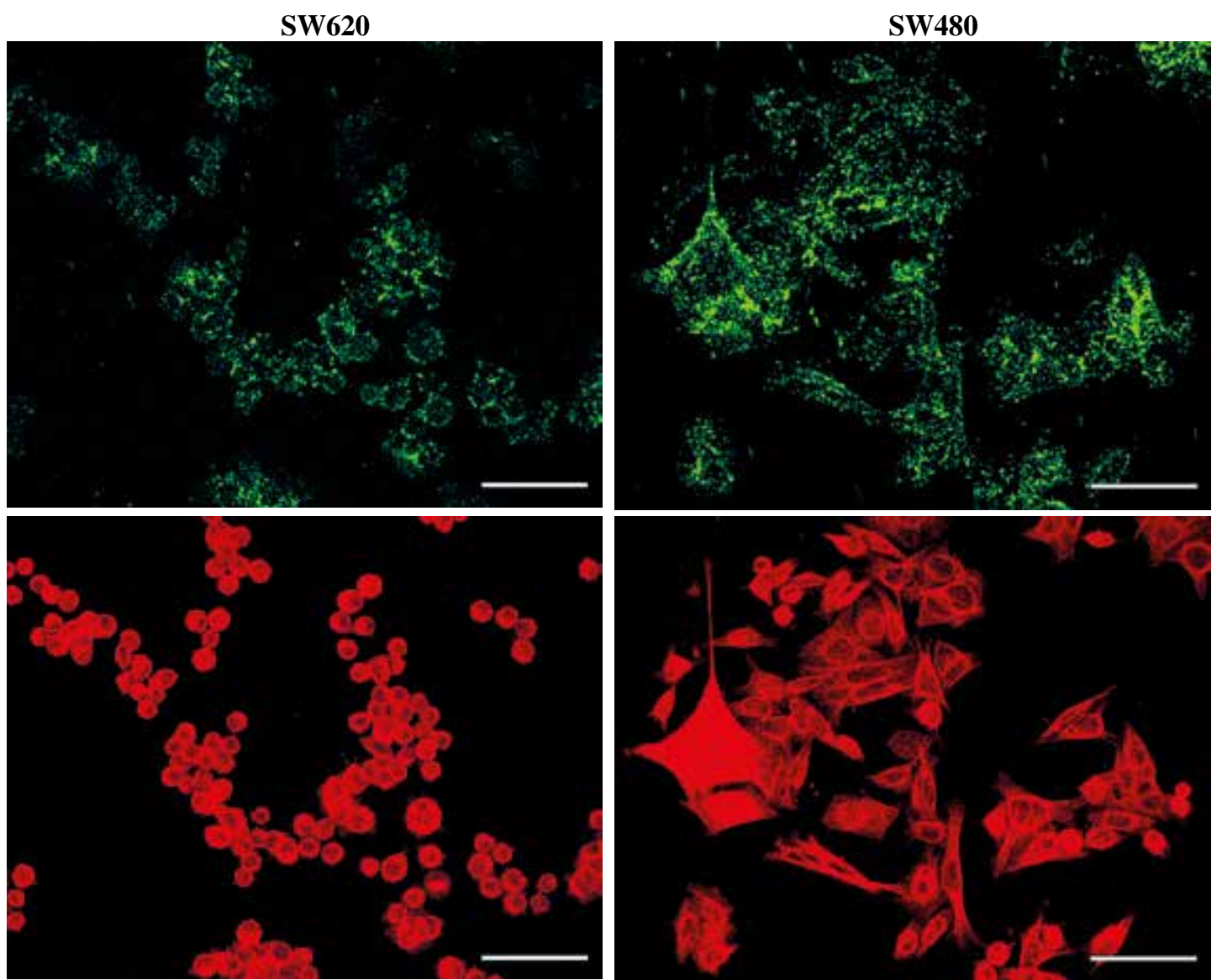

CD59
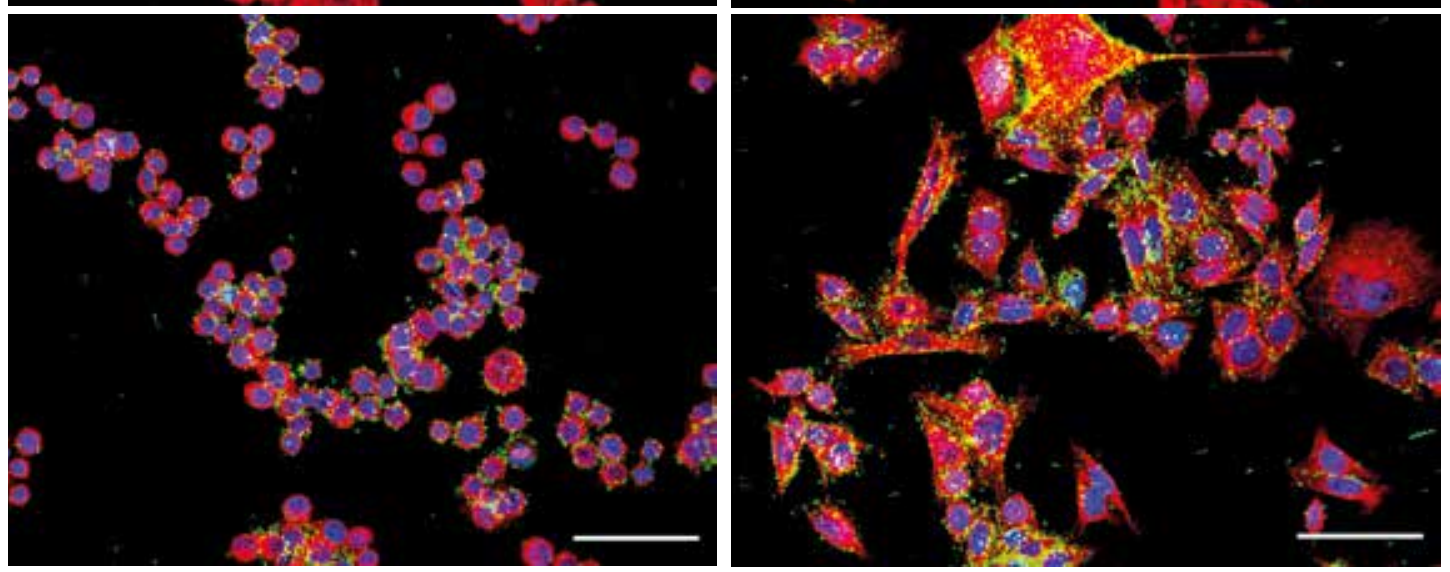

$\alpha$-tubulin

CD59 $\alpha$-tubulin DAPI

Fig. 3. CD46 immunoreactivity (green) in SW480 and SW620 cell lines. To visualize cell morphology $\alpha$-tubulin staining was applied (red), cell nuclei were stained with DAPI (blue); scale $50 \mu \mathrm{m}$

and CD59 expression in breast cancer was found to be to some extent compensated by the high CD46 expression [14]. However, most of the literature report the contrary, i.e. an increased CD55 and CD59 expression in tumors like melanoma, osteosarcoma, prostate, ovarian and stomach cancer [15-18].

Some authors suggest a relationship between CD59 expression and the degree of tumor differentiation. In high and medium-differentiated tumors, CD59 expression was found to be higher when compared with cancers with a low degree of differentiation $[19,20]$.

Surprisingly, a large variation in the level of membrane-bound regulator expression occurs between different cases of the same tumor. For example, a large variation in complement regulator expression occurs in breast and kidney cancers [21]. In breast cancer, a low CD55 and CD59 expression level was detected in poorly differentiated carcinomas, what additionally correlated with a worse out- 

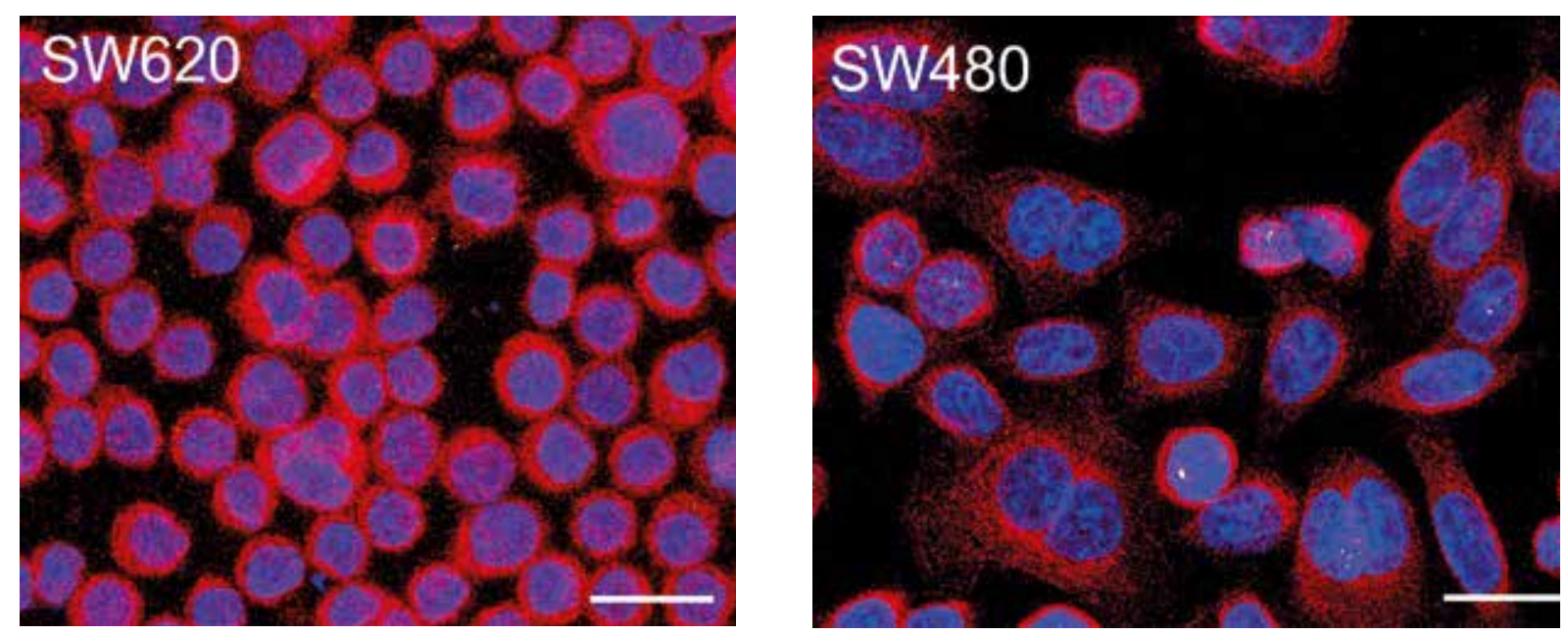

Fig. 4. Control immunoreaction with immunoglobulins applied instead of the primary antibody (green); to visualize cell morphology $\alpha$-tubulin staining was applied (red), cell nuclei were stained with DAPI (blue); scale bar $20 \mu \mathrm{m}$

come $[22,23]$. On the other hand, an increased CD59 expression in this type of carcinoma was also reported [24].

The use of monoclonal antibodies in cancer therapy has been given a lot of attention in recent years, especially after the clinical success of such drugs as rituximab and trastuzumab $[25,26]$. However, for a large fraction of monoclonal antibodies, the effectiveness of immunotherapy is not satisfactory. To increase the efficiency of the therapy and to facilitate removal of tumor cells by specific antibodies and activated complement system, new strategies are sought. Some studies demonstrate an increased cytotoxic effect after blocking the activity of specific complement-regulatory proteins on the surface of cancer cells. In most reported cases, this modification effectively increases the susceptibility of tumor cells to the lytic effect of complement. For example, blocking the function of CD55 in leukemia, melanoma or breast cancer resulted in increased susceptibility of these cells to the complement activation $[27,28]$. However, the effect of anti-CD55 antibody was negligible in the case of renal cancer and small in ovarian, and prostate cancer cells $[28,29]$. In the latter work, results are quite surprising, since these prostate cancer cells expressed CD55 at a high level, and still, its blocking was not sufficient to sensitize them to the complement attack. Similarly, when CD46 molecule was blocked, it did not significantly increase the percentage of lysis of K562 leukemic and cervical cancer cell lines [30, 31]. The research of CD59 is most conclusive; neutralization of this inhibitor significantly affected neuroblastoma, leukemia, breast cancer, ovarian, kidney, and prostate cancer cell death [27-30, 32,33 . It seems that the function of particular complement regulators varies between cancer cells of different origin.

CD46, except its membrane-bound form, could be released in a form of vesicles from cancer cells into tumour microenvironment [34]. The vesicles containing this inhibitor can thus act in proximity of tumour, by inhibiting the inflammation process and complement deposition. The high expression of CD46 on colon cancer cells not only influences its survival but additionally can modulate the microenvironment in order to facilitate the migration and metastasis formation. Thus, further studies are needed to evaluate whether the removal or blockade of this specific complement inhibitor on colon cancer cells surface can affect vitally patients' survival in a disease-free state.

This study was supported by the State Committee for Scientific Research, grant S3 PO5B 09724.

\section{References}

1. Noguchi T, Ritter G, Nishikawa H (2013): Antibody-based therapy in colorectal cancer. Immunotherapy 5: 533-545.

2. Gołąb JM (2002): Odporność nieswoista, układ dopełniacza. In: Immunologia. Wydawnictwo Naukowe PWN, Warszawa; 169-183.

3. Liszewski MK, Farries TC, Lublin DM, et al. (1996): Control of the complement system. Adv Immunol 61: 201-283.

4. Riley-Vargas RC, Gill DB, Kemper C, et al. (2004): CD46: expanding beyond complement regulation. Trends Immunol 25: 496-503.

5. Nicholson-Weller A, Burge J, Fearon DT, et al. (1982): Isolation of a human erythrocyte membrane glycoprotein with decay-accelerating activity for $\mathrm{C} 3$ convertases of the complement system. J Immunol 129: 184-189.

6. Kinoshita T, Medof ME, Silber R, Nussenzweig V (1985): Distribution of decay-accelerating factor in the peripheral blood of normal individuals and patients with paroxysmal nocturnal hemoglobinuria. J Exp Med 162: 75-92. 
7. Medof ME, Walter EI, Rutgers JL, et al. (1987): Identification of the complement decay-accelerating factor (DAF) on epithelium and glandular cells and in body fluids. J Exp Med 165: 848-864.

8. Nicholson-Weller A, March JP, Rosen CE, et al. (1985): Surface membrane expression by human blood leukocytes and platelets of decay-accelerating factor, a regulatory protein of the complement system. Blood 65: 1237-1244.

9. Asch AS, Kinoshita T, Jaffe EA, Nussenzweig V (1986): Decay-accelerating factor is present on cultured human umbilical vein endothelial cells. J Exp Med 163: 221-226.

10. Stefanová I, Hilgert I, Kristofová H, et al. (1989): Characterization of a broadly expressed human leucocyte surface antigen MEM-43 anchored in membrane through phosphatidylinositol. Mol Immunol 26: 153-161.

11. Meri S, Morgan BP, Davies A, et al. (1990): Human protectin (CD59), an 18,000-20,000 MW complement lysis restricting factor, inhibits C5b-8 catalysed insertion of C9 into lipid bilayers. Immunology 71: 1-9.

12. Rollins SA, Sims PJ (1990): The complement-inhibitory activity of CD59 resides in its capacity to block incorporation of C9 into membrane C5b-9. J Immunol 144: 3478-3483.

13. Leibovitz A, Stinson JC, McCombs WB 3rd, et al. (1976): Classification of human colorectal adenocarcinoma cell lines. Cancer Res 36: 4562-4569.

14. Madjd Z, Durrant LG, Pinder SE, et al. (2005): Do poor-prognosis breast tumours express membrane cofactor proteins (CD46)? Cancer Immunol Immunother 54: 149-156.

15. Brasoveanu LI, Altomonte M, Gloghini A, et al. (1995): Expression of protectin (CD59) in human melanoma and its functional role in cell- and complement-mediated cytotoxicity. Int J Cancer 61: 548-556.

16. Jarvis GA, Li J, Hakulinen J, et al. (1997): Expression and function of the complement membrane attack complex inhibitor protectin (CD59) in human prostate cancer. Int J Cancer 71: 1049-1055.

17. Bjřrge L, Hakulinen J, Wahlström T, et al. (1997): Complement-regulatory proteins in ovarian malignancies. Int J Cancer 70: 14-25.

18. Li L, Spendlove I, Morgan J, Durrant LG (2001): CD55 is over-expressed in the tumour environment. Br J Cancer 84: 80-86.

19. Koretz K, Brüderlein S, Henne C, Möller P (1993): Expression of CD59, a complement regulator protein and a second ligand of the CD2 molecule, and CD46 in normal and neoplastic colorectal epithelium. Br J Cancer 68: 926-931.

20. Bjřrge L, Vedeler CA, Ulvestad E, Matre R (1994): Expression and function of CD59 on colonic adenocarcinoma cells. Eur J Immunol 24: 1597-1603.

21. Meri S, Jarva H (2001): Complement regulatory proteins. Article online. Encyclopedia of life sciences Nature Publishing Group, Macmillan Reference Ltd.

22. Madjd Z, Durrant LG, Bradley R, et al. (2004): Loss of CD55 is associated with aggressive breast tumors. Clin Cancer Res 10: $2797-2803$.

23. Madjd Z, Pinder SE, Paish C, et al. (2003): Loss of CD59 expression in breast tumours correlates with poor survival. J Pathol 200: 633-639.

24. Hakulinen J, Meri S (1994): Expression and function of the complement membrane attack complex inhibitor protectin (CD59) on human breast cancer cells. Lab Invest 71: 820-827.

25. Carter P (2001): Improving the efficacy of antibody-based cancer therapies. Nat Rev Cancer 1: 118-129.
26. Ross JS, Gray K, Gray GS, et al. (2003): Anticancer antibodies. Am J Clin Pathol 119: 472-485.

27. Golay J, Lazzari M, Facchinetti V, et al. (2001): CD20 levels determine the in vitro susceptibility to rituximab and complement of B-cell chronic lymphocytic leukemia: further regulation by CD55 and CD59. Blood 98: 3383-3389.

28. Donin N, Jurianz K, Ziporen L, et al. (2003): Complement resistance of human carcinoma cells depends on membrane regulatory proteins, protein kinases and sialic acid. Clin Exp Immunol 131: 254-263.

29. Gorter A, Blok VT, Haasnoot WH, et al. (1996): Expression of CD46, CD55, and CD59 on renal tumor cell lines and their role in preventing complement-mediated tumor cell lysis. Lab Invest 74: 1039-1049.

30. Jurianz K, Ziegler S, Donin N, et al. (2001): K562 erythroleukemic cells are equipped with multiple mechanisms of resistance to lysis by complement. Int J Cancer 93: 848-854.

31. Gelderman KA, Blok VT, Fleuren GJ, Gorter A (2002): The inhibitory effect of CD46, CD55, and CD59 on complement activation after immunotherapeutic treatment of cervical carcinoma cells with monoclonal antibodies or bispecific monoclonal antibodies. Lab Invest 82: 483-493.

32. Gasque P, Thomas A, Fontaine M, Morgan BP (1996): Complement activation on human neuroblastoma cell lines in vitro: route of activation and expression of functional complement regulatory proteins. J Neuroimmunol 66: 29-40.

33. Jurianz K, Maslak S, Garcia-Schüler H, et al. (1999): Neutralization of complement regulatory proteins augments lysis of breast carcinoma cells targeted with rhumAb anti-HER2. Immunopharmacology 42: 209-218.

34. Hakulinen J, Junnikkala S, Sorsa T, Meri S (2004): Complement inhibitor membrane cofactor protein (MCP; CD46) is constitutively shed from cancer cell membranes in vesicles and converted by a metalloproteinase to a functionally active soluble form. Eur J Immunol 34: 2620-2629. 